\title{
Role of Ru on the Microstructural Evolution During Long-Term Aging of Ni-Based Single Crystal Superalloys
}

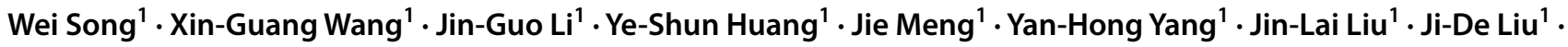 \\ Yi-Zhou Zhou ${ }^{1} \cdot$ Xiao-Feng Sun ${ }^{1}$
}

Received: 8 April 2020 / Revised: 20 May 2020 / Accepted: 21 May 2020 / Published online: 29 July 2020

(c) The Chinese Society for Metals (CSM) and Springer-Verlag GmbH Germany, part of Springer Nature 2020

\begin{abstract}
Two experimental alloys containing different contents of Ru were investigated to study the effect of Ru on the microstructural evolution during long-term thermal exposure. The increase in Ru promoted the formation of cubical, tiny, and even $\gamma^{\prime}$ phase after full heat treatment. Moreover, the samples after full heat treatment were exposed at $1100{ }^{\circ} \mathrm{C}$ for different time. Based on the classical model by Lifshitz, Slyozov, and Wagner, the coarsening of $\gamma^{\prime}$ phase of the alloy containing 2.5 and 3.5 wt. \% Ru during the long-term aging was controlled by the interface reaction and diffusion, respectively. The $\gamma / \gamma^{\prime}$ lattice misfit was more negative with the increment of Ru addition, which induced the formation of stable rafted $\gamma^{\prime}$ phase in the alloy containing $3.5 \mathrm{wt} . \% \mathrm{Ru}$ at the initiation of long-term aging. Besides, the increase in Ru reduced the diffusion coefficient, which could restrain the $\gamma^{\prime}$ phase coarsening. The lower $\gamma / \gamma^{\prime}$ lattice misfit of the alloy containing $2.5 \mathrm{wt}$. $\%$ Ru promoted the interface reaction, which induced the rapid coarsening of $\gamma^{\prime}$ phase. Therefore, the increase in Ru improved the microstructural stability of the alloys. On the other hand, the raise of Ru induced "reverse partitioning" behavior, which was effective in suppressing the emergence of the topologically close-packed phase (TCP phase). The TCP phase occasionally occurred in the alloy containing $2.5 \mathrm{wt} . \% \mathrm{Ru}$, which was attributed to the high temperature and the supersaturation of the $\gamma$ matrix. Moreover, the TCP phase was determined as $\mu$ phase, which had a high concentration of Co, Re, Mo, and W. A sketch map describing the evolution of the TCP phase was also constructed.
\end{abstract}

Keywords Ni-based superalloys $\cdot$ Ruthenium $\cdot$ Coarsening $\cdot$ TCP phase

\section{Introduction}

Nickel-based single crystal superalloys have been the outstanding candidate materials for aerospace, gas turbine, and energy chemical industry due to its prominent creep and oxidation resistance at elevated temperatures [1-4]. In pace with the continuous increase in the turbine inlet temperatures [5], the service temperatures of superalloys need

Available online at http://link.springer.com/journal/40195.

Xin-Guang Wang

xgwang11b@imr.ac.cn

$\triangle$ Jin-Guo Li

jgli@imr.ac.cn

$\triangle$ Xiao-Feng Sun

xfsun@imr.ac.cn

1 Superalloys Division, Institute of Metal Research, Chinese Academy of Sciences, Shenyang 110016, China further improvement. Therefore, in recent years, a considerable quantity of refractory elements such as Re, W, and Mo is added to superalloys to enhance the solution strengthening effects and oxidation resistance properties, which can significantly improve the service temperatures. However, these refractory elements especially Re are contributed to the formation of topologically closed-packed phase (TCP phase) and secondary reaction zone (SRZ) during long-term service [6-9], which depletes the solution strengthening elements and deteriorates the microstructural stability. Therefore, the mechanical properties of the alloys during long-term operation at elevated temperatures are severely decreased. To further eliminate the defect which brings from refractory elements, $\mathrm{Ru}$ element is added to the alloys to suppress the appearance of these problems. The addition of Ru can hinder the coarsening of the $\gamma^{\prime}$ phase and the formation of the TCP phase by the reverse partitioning of elements [10], which improves microstructural stability and creep resistance. Moreover, the addition of Ru can decrease the average size 
of the initial $\gamma^{\prime}$ phase and promote the formation of stable rafting microstructures during the long-term operation [11], which is propitious to the microstructural stability.

The long-term aging experiment is crucial, which can be a reference for the microstructural stability of the superalloys during the real service. Based on the previous works [12-15], the microstructural evolution of different single crystal alloys during long-term aging has been investigated in quantities. However, little studies focus on the effect of $\mathrm{Ru}$ on the microstructure and TCP evolution of the alloys during long-term aging at high temperature. Besides, the TCP phase occurs in the alloy containing low Ru content, which is consistent with previous papers [16-19]. Therefore, to further research the influence of Ru on the microstructure and TCP evolution, the elements segregation and the coarsening of $\gamma^{\prime}$ phase, the long-term aging experiments of two alloys (2.5 wt.\% Ru and $3.5 \mathrm{wt} . \% \mathrm{Ru}$ ) are carried out. The paper is for better expounding the influence of Ru element on the microstructural evolution during the long-term thermal exposure. Furthermore, it also can promote the development of the composition design of the Ni-based superalloys with microstructural stability under high temperatures.

\section{Experimental}

The effect of Ru on the microstructural evolution during the long-term aging was investigated via the two different Ru-containing alloys. Based on the variation of Ru content, two alloys were named as alloy $2.5 \mathrm{Ru}$ and alloy $3.5 \mathrm{Ru}$, respectively. The chemical compositions of the two alloys are listed in Table 1. The vacuum induction technique was applied to melt the two alloys. After that, both alloys were directionally solidified into long staff. The electron backscatter diffraction (EBSD) was applied to select the bars within $5^{\circ}$ off [001] orientation. The differential thermal analysis (DTA) and metallographic method were used to confirm the heat treatments of the two alloys, which were as follows: $1325^{\circ} \mathrm{C} / 16 \mathrm{~h}+1335^{\circ} \mathrm{C} / 16 \mathrm{~h}+\mathrm{AC}$ (air cooling) $\rightarrow 1150{ }^{\circ} \mathrm{C}$ $14 \mathrm{~h}+\mathrm{AC} \rightarrow 870{ }^{\circ} \mathrm{C} / 24 \mathrm{~h}+\mathrm{AC}$ for alloy $2.5 \mathrm{Ru} ; 1320^{\circ} \mathrm{C}$ $/ 16 \mathrm{~h}+1325{ }^{\circ} \mathrm{C} / 16 \mathrm{~h}+\mathrm{AC} \rightarrow 1150{ }^{\circ} \mathrm{C} / 4 \mathrm{~h}+\mathrm{AC} \rightarrow 870{ }^{\circ} \mathrm{C}$ $/ 24 \mathrm{~h}+\mathrm{AC}$ for alloy $3.5 \mathrm{Ru}$. To accurately acquire the $\gamma / \gamma^{\prime}$ partitioning ratio of each alloying element of the complete heat treated specimens which were coarsened at $1310^{\circ} \mathrm{C}$ $/ 1 \mathrm{~h}+\left(1150-1310^{\circ} \mathrm{C}\right) / 12 \mathrm{~h}+\mathrm{AC}$, electron probe microanalysis (EPMA) was applied to measure the local chemical composition of the $\gamma$ and $\gamma^{\prime}$ phase. Samples after above heat treatments were cut into 5-7 $\mathrm{mm}$ for long-term aging at $1100{ }^{\circ} \mathrm{C}$ to study the influence of $\mathrm{Ru}$ on microstructural evolution. The specimens after long-term aging for $100 \mathrm{~h}$, $200 \mathrm{~h}, 500 \mathrm{~h}$, and $1000 \mathrm{~h}$ were polished and etched in a solution of $\mathrm{HCl}(100 \mathrm{ml})+\mathrm{CuSO}_{4}(20 \mathrm{~g})+\mathrm{H}_{2} \mathrm{O}(80 \mathrm{ml})+\mathrm{H}_{2} \mathrm{SO}_{4}$ $(5 \mathrm{ml})$. Then, the microstructure was observed by optical microscopy (OM) and Inspect F50 field emission scanning electron microscopy (FESEM). Besides, the electron probe microanalysis (EPMA) was applied to measure the local chemical compositions after $1000 \mathrm{~h}$ exposure of the $\gamma$ and $\gamma^{\prime}$ phases, and the $\gamma / \gamma^{\prime}$ lattice misfit of specimens is obtained by the X-ray diffraction (XRD) method.

The selected area diffraction patterns (SADP) of TCP phases were obtained via the transmission electron microscope (TEM) to confirm the type of TCP phase. The TEM specimens were sectioned from the long-term aging samples and mechanically ground to about $50 \mu \mathrm{m}$ in thickness and electrochemically polished by a twin jet polisher.

\section{Results}

\subsection{Initial Microstructure}

Figure 1 exhibits the as-cast microstructures of the two alloys. It is obvious that the volume fraction of the eutectic increases with the raise of $\mathrm{Ru}$, which is $3.5 \% \pm 0.8 \%$ and $8.7 \% \pm 1.3 \%$ of the two alloys, respectively. The primary dendrite arm spacing of the two alloys is $270.1 \pm 6.8 \mu \mathrm{m}$ and $246.3 \pm 5.9 \mu \mathrm{m}$, respectively, which decreases significantly with the increase in Ru. Moreover, the dendritic patterns show high parallelism, which demonstrates that the alloys grow along with [001] orientation well. Based on the SEM images after full heat treatment of the two alloys (as shown in Fig. 2a, c [20]), the typical $\gamma / \gamma^{\prime}$ two-phase microstructure is observed. The $\gamma^{\prime}$ phase is increasingly cuboidal and uniform with the increase in Ru. Besides, the average size of the $\gamma^{\prime}$ precipitate of the two alloys is $0.385 \mu \mathrm{m}$ and $0.345 \mu \mathrm{m}$, respectively (as shown in Fig. 2b, d [20]), which also decreases remarkably with the increase in $\mathrm{Ru}$. The volume fraction of the $\gamma^{\prime}$ phase of the two alloys is another important parameter, which is $66.1 \%$ and $63.4 \%$, respectively. Figure 3 indicates that the alloying elements show the so-called reverse partitioning behavior with the increase in $\mathrm{Ru}$. The "reverse partitioning" behavior means that Ru promotes the $\gamma$-forming elements, such as $\mathrm{Re}, \mathrm{Mo}$, and $\mathrm{Cr}$ to partition to the $\gamma^{\prime}$ phase and the
Table 1 Chemical compositions of the two alloys (wt.\%)

\begin{tabular}{lllllllll}
\hline Alloy & $\mathrm{Co}$ & $\mathrm{Cr}$ & $\mathrm{W}+\mathrm{Mo}+\mathrm{Ta}$ & $\mathrm{Re}$ & $\mathrm{Ru}$ & $\mathrm{Al}$ & $\mathrm{Hf}$ & $\mathrm{Ni}$ \\
\hline $2.5 \mathrm{Ru}$ & 11.7 & 4 & 15.4 & 5 & 2.5 & 6.2 & 0.1 & $\mathrm{Bal}$ \\
$3.5 \mathrm{Ru}$ & 11.7 & 4 & 15.4 & 5 & 3.5 & 6.2 & 0.1 & $\mathrm{Bal}$ \\
\hline
\end{tabular}



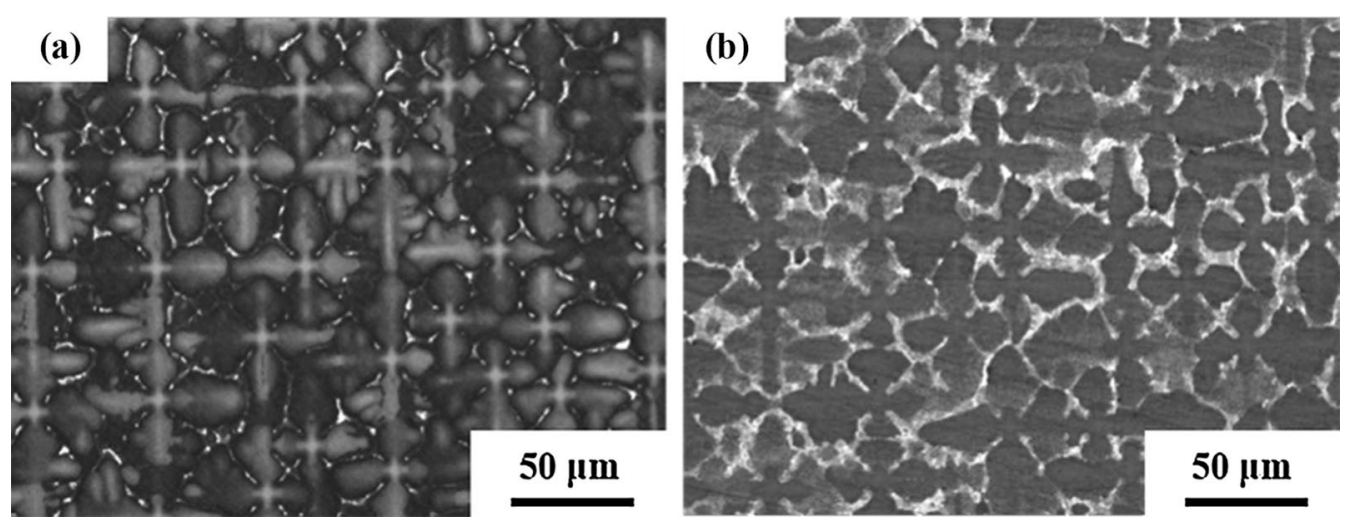

Fig. $1 \mathrm{OM}$ images of the as-cast microstructures of the two alloys: a alloy $2.5 \mathrm{Ru}, \mathbf{b}$ alloy $3.5 \mathrm{Ru}$
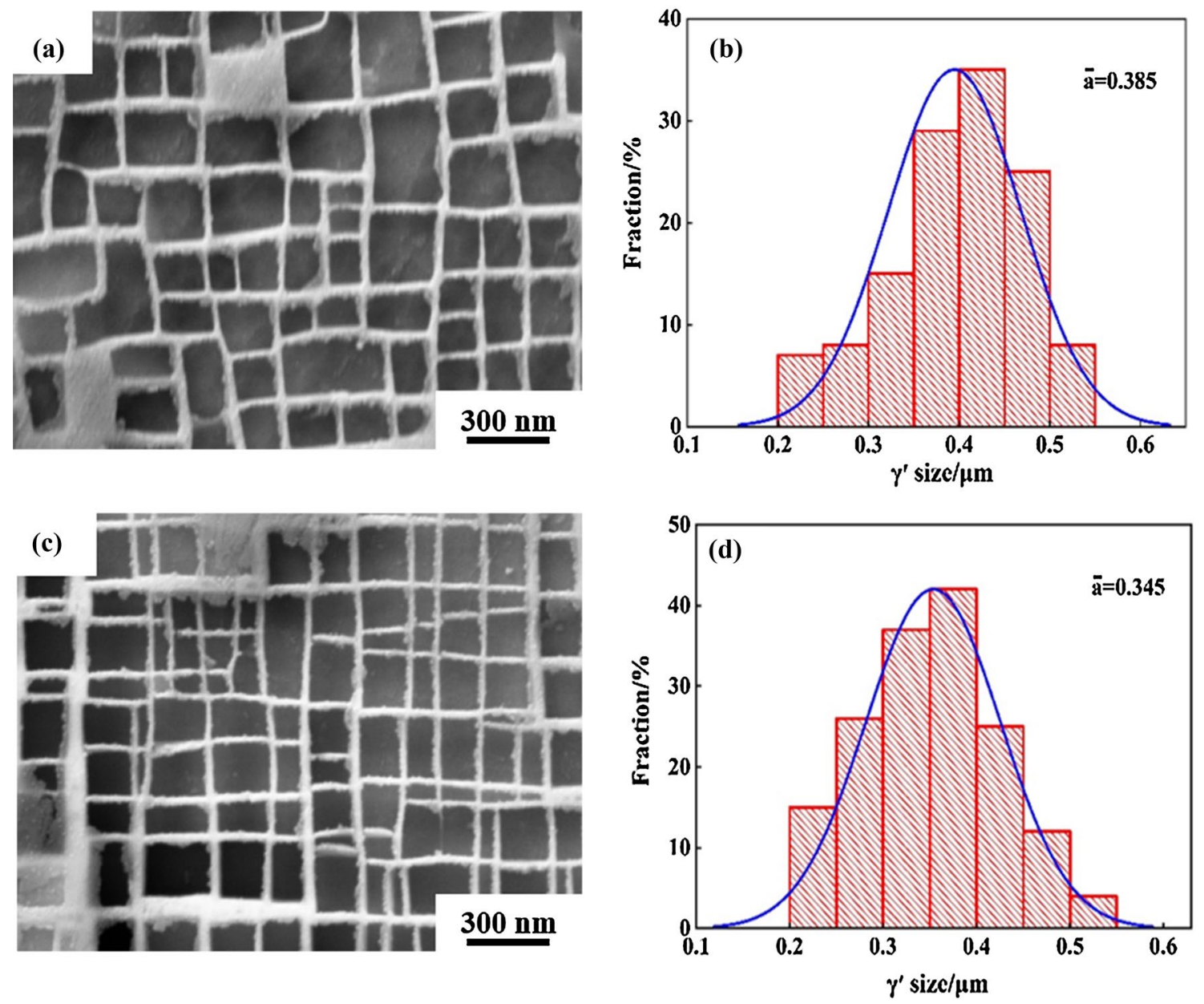

Fig. 2 Microstructures after full heat treatment and average size of the $\gamma^{\prime}$ phase: $\mathbf{a}, \mathbf{b}$ alloy $2.5 \mathrm{Ru}, \mathbf{c}, \mathbf{d}$ alloy $3.5 \mathrm{Ru}$ [20]

$\gamma^{\prime}$-forming elements, such as $\mathrm{Al}, \mathrm{Ta}$, and $\mathrm{Ni}$ to partition to the $\gamma$ matrix. According to the above analyses, the increase in $\mathrm{Ru}$ reduces the average size of the $\gamma^{\prime}$ precipitate and makes the $\gamma^{\prime}$ precipitate more cuboidal and uniform, which 


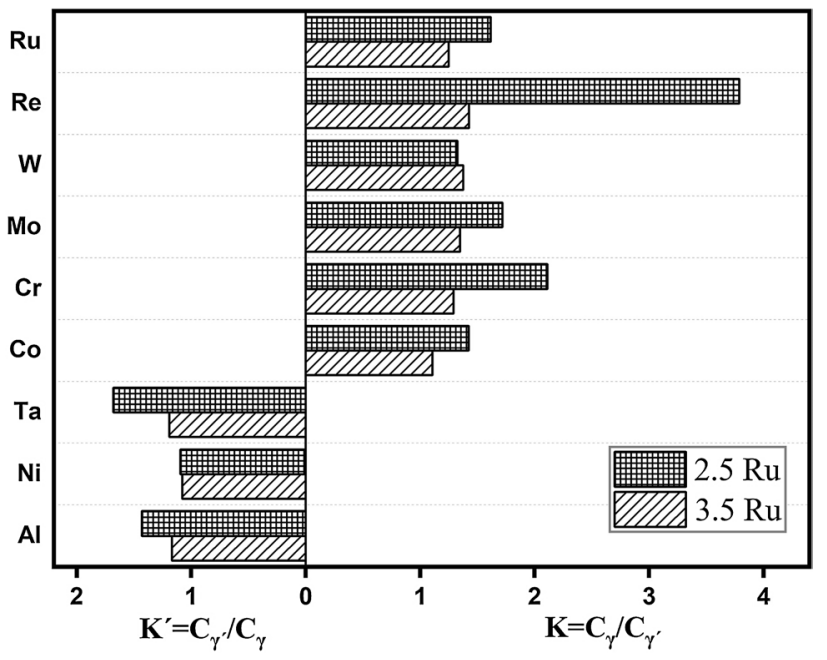

Fig. 3 The $\gamma / \gamma^{\prime}$ partitioning ratio of each alloying element in the two alloys
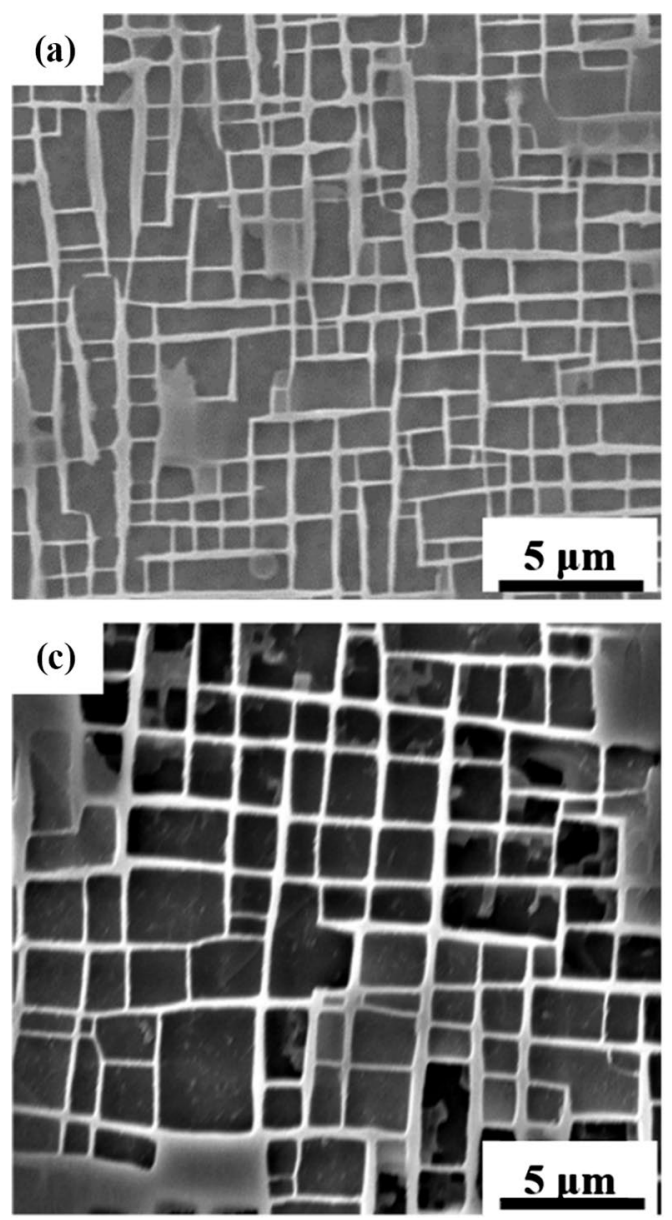

is profitable for the microstructural stability and mechanical properties.

\subsection{Microstructure After Long-Term Aging}

Figure 4 exhibits the microstructures after long-term aging of the alloy $2.5 \mathrm{Ru}$. Several features of the microstructures can be concluded: (a) The $\gamma^{\prime}$ precipitate keeps cuboidal before $500 \mathrm{~h}$ and is rafted at $1000 \mathrm{~h}$. The rafted microstructures distribute unevenly, which shows the so-called topological inversion phenomenon [21]; (b) some $\gamma$ matrix is vanishing with the increase in time, which is marked as a red triangle. Based on Fig. 5a, the coarsening of $\gamma^{\prime}$ precipitate is prominent. The disappearance of $\gamma$ matrix provides composition conditions for the coarsening of the $\gamma^{\prime}$ phase. The primary controlling factors of the coarsening will be discussed in Sect. 4.1. Figure 4 shows the SEM images of the alloy $3.5 \mathrm{Ru}$ after long-term thermal exposure. According to the microstructures, it can be concluded: (a) the rafted $\gamma^{\prime}$ phase is observed at the initiation of long-term aging, which exhibits regular and uniform. The topological inversion phenomenon does not emerge during the entire process
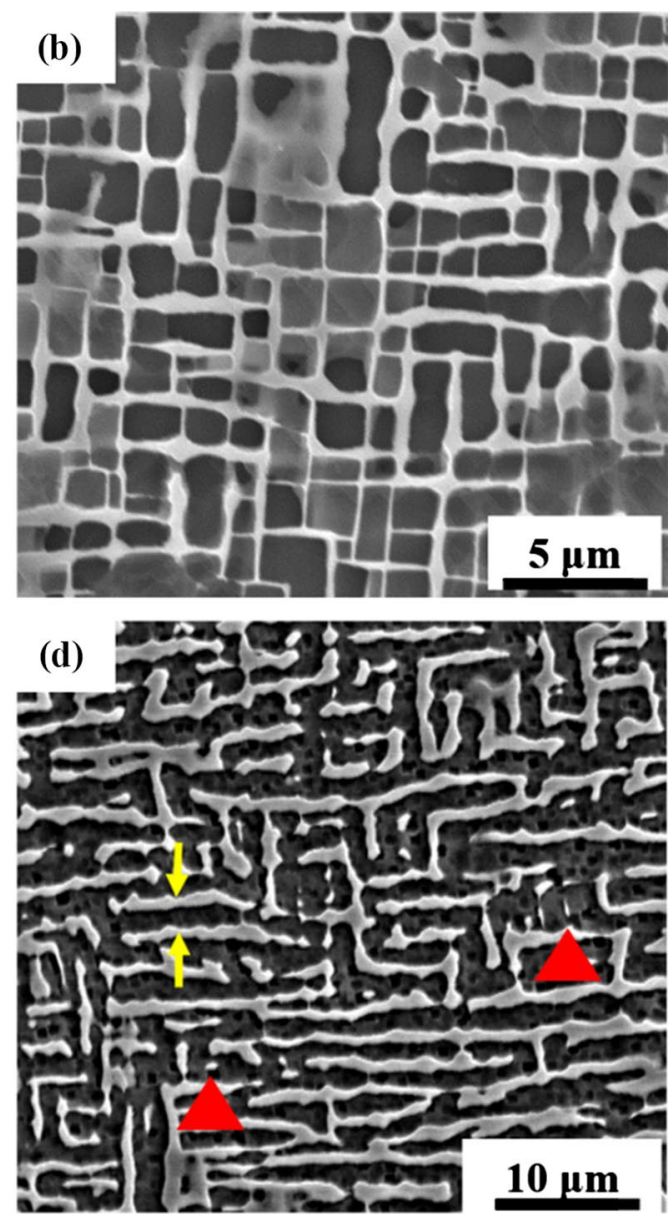

Fig. 4 SEM images of alloy $2.5 \mathrm{Ru}$ after long-term aging at $1100^{\circ} \mathrm{C}$ : a $100 \mathrm{~h}, \mathbf{b} 200 \mathrm{~h}, \mathbf{c} 500 \mathrm{~h}, \mathbf{d} 1000 \mathrm{~h}$ 

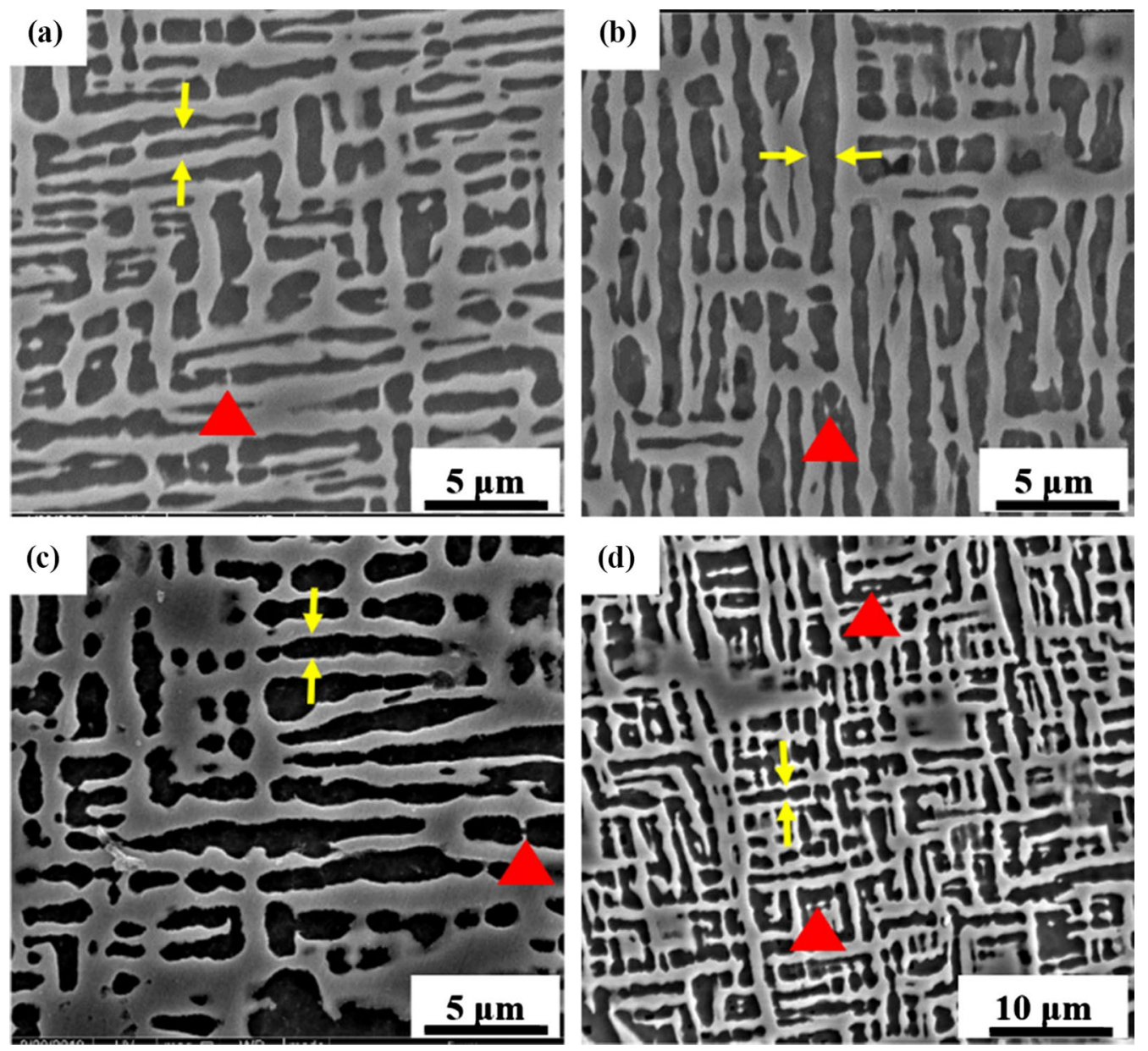

Fig. 5 SEM images of alloy $3.5 \mathrm{Ru}$ after long-term aging at $1100^{\circ} \mathrm{C}$ : a $100 \mathrm{~h}, \mathbf{b} 200 \mathrm{~h}, \mathbf{c} 500 \mathrm{~h}, \mathbf{d} 1000 \mathrm{~h}$
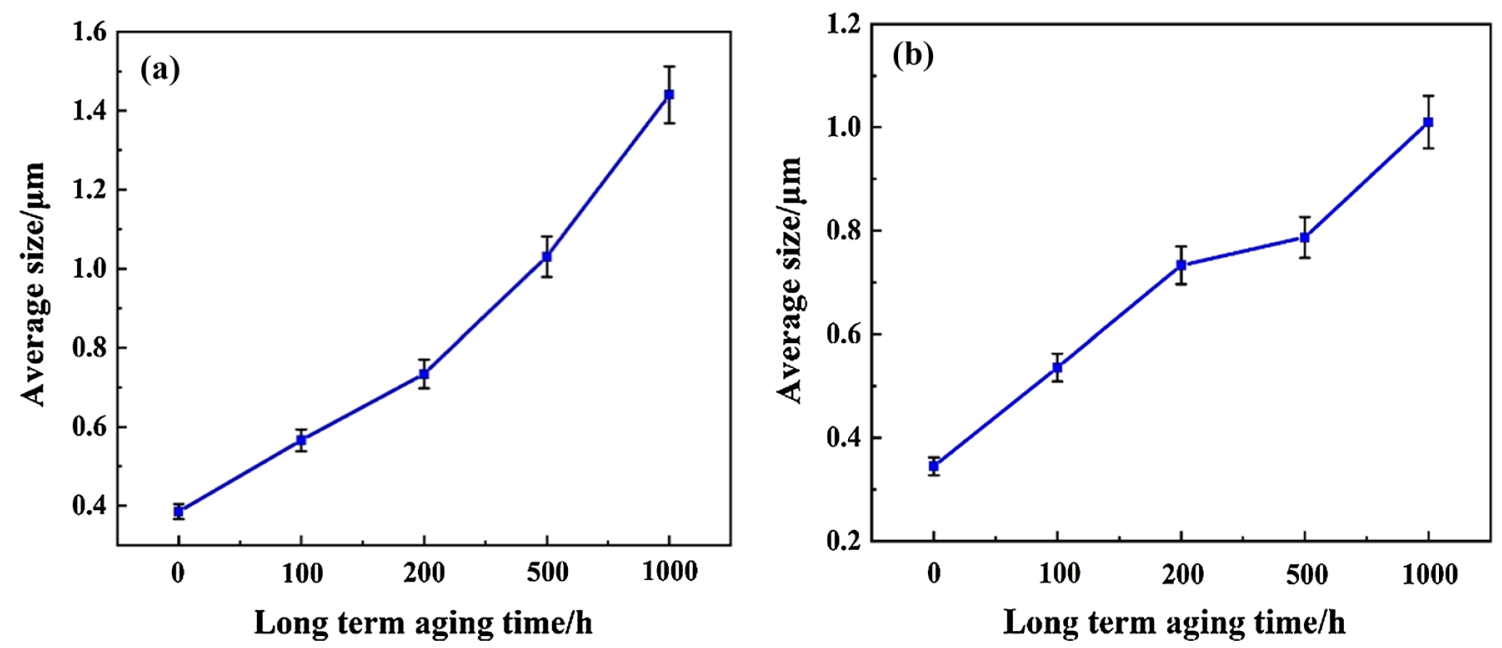

Fig. 6 Average size of the $\gamma^{\prime}$ phase after long-term aging at $1100^{\circ} \mathrm{C}$ with different time: a alloy $2.5 \mathrm{Ru}, \mathbf{b}$ alloy $3.5 \mathrm{Ru}$ 
of the experiment. (b) The vanishing $\gamma$ matrix is frequently observed (as shown in Fig. 5), while the average size of the rafted $\gamma^{\prime}$ phase increases slowly (as shown in Fig. 6b). It is indicated that the increase in $\mathrm{Ru}$ influences the diffusion of other elements, which suppresses the coarsening of $\gamma^{\prime}$ phase. The relevant analysis will be shown in Sect. 4.1.

\subsection{TCP Phase}

Based on the observation and analysis of a large number of the specimen, the TCP phase only occasionally emerges in the microstructures after long-term aging of alloy $2.5 \mathrm{Ru}$. The quantity of the TCP phase continually increases as the time goes on and reaches the maximum at $1000 \mathrm{~h}$. The TCP phase is often encompassed by the $\gamma$ matrix and shown as the shape of bulk-like or rod-like. Besides, the TCP phase seldom emerges in the superalloys containing Ru due to the so-called reverse partitioning behavior. However, in this experiment, it appears occasionally in alloy $2.5 \mathrm{Ru}$, which must be the result of the effect of $\mathrm{Ru}$ on the segregation behavior of other elements. The composition and type of the TCP phase will be discussed in the subsequent chapter.

\section{Discussion}

\subsection{Effect of Ru on the Microstructure Evolution}

The influence of $\mathrm{Ru}$ on the microstructural evolution is mainly discussed from two factors: the influence of Ru on the diffusion of other elements and the effect of $\mathrm{Ru}$ on the energy on $\gamma / \gamma^{\prime}$ interface. In reality, the coarsening of $\gamma^{\prime}$ phase is the predominant microstructural evolution during the long-term aging. The above two factors are also mainly about the coarsening of the $\gamma^{\prime}$ phase. Therefore, according to the LSW theory [22], when the coarsening is determined by elements diffusion, the following formula will be applied:

$\bar{r}^{3}-\bar{r}_{0}^{3}=K t$.

where $\bar{r}^{3}$ is the initial particle radius, $\bar{r}^{3}$ is the instantaneous particle radius, $K$ is the rate constant, and $t$ is the coarsening time. When the size of the $\gamma^{\prime}$ precipitate is defined as $a$, it is obvious that $\bar{r}=a / 2$ and $\bar{r}=a_{0} / 2$. Here, it should be pointed that in order to obtain the size of the $\gamma^{\prime}$ precipitate accurately, we only deem that the width which is marked as the space between the two yellow arrows (as shown in Figs. 4 and 5) of the rafted $\gamma^{\prime}$ precipitate is the valid data. Hence, based on Eq. (1), fitting straight line of $(a / 2)^{3}-\left(a_{0} / 2\right)^{3}$ versus $t$ is established (as shown in Fig. 7a) to confirm the controlling mechanism of the $\gamma^{\prime}$ precipitates coarsening. It is obvious that alloy 3.5 Ru shows an excellent linear fit, which means that the coarsening of $\gamma^{\prime}$ precipitates is controlled by the diffusion. Besides, the variable linear slope represents the different diffusion coefficient of the two alloys, which is related to the increase in $\mathrm{Ru}$. To further determine the effect of $\mathrm{Ru}$ on the diffusion coefficient, the mathematical relationship between the $D$ (diffusion coefficient) and $K$ (rate constant) is confirmed. According to the LSW theory, $K$ can be defined as the following formula [23]:

$K=\frac{2 F D C_{\mathrm{e}} V_{\mathrm{m}}^{2}}{\rho_{\mathrm{C}}^{2} R T}$.

where $F$ is the free energy on the $\gamma / \gamma^{\prime}$ interface, $D$ is the diffusion coefficient, $C_{\mathrm{e}}$ is the content of $\gamma^{\prime}$ forming elements, $V_{\mathrm{m}}$ is the molar volume of precipitates, $\rho_{\mathrm{c}}$ is the numerical constant $\left(\rho_{\mathrm{c}}=3 / 2\right)$, and $R$ and $T$ are the gas constant and absolute temperature, respectively. Here, because the longterm aging temperature of the two alloys is the same, $\rho_{\mathrm{c}}, R$,
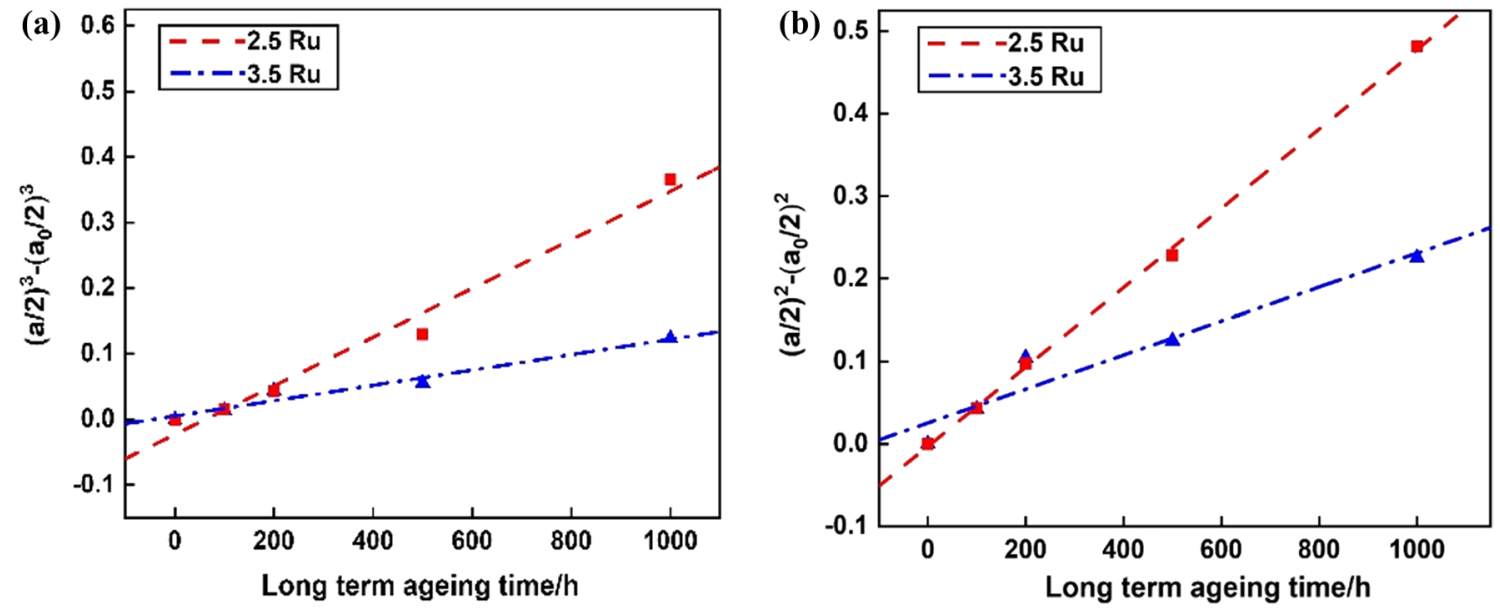

Fig. 7 Fitting straight line of the second and third power of $\gamma^{\prime}$ size with time: a third power, $\mathbf{b}$ second power 
and $T$ are constant. The interface free energy $F$ is mainly decided by the $\gamma / \gamma^{\prime}$ interfacial structure and the chemistry of interface, which are rarely influenced by the increase in $\mathrm{Ru}$. As Ru induces "reverse partitioning" behavior, the $C_{\mathrm{e}}$ and $V_{\mathrm{m}}$ are influenced by the increase in Ru. Therefore, Eq. (2) can be simplified as:

$D=A \frac{K}{C_{\mathrm{e}} V_{m}^{2}}$.

where $A$ is a constant as $A=\frac{9 R T}{8 F}$. However, the elements show slight "reverse partitioning" behavior, and the $C_{\mathrm{e}}$ can be further ignored or regarded as constant. The $V_{\mathrm{m}}$ is proportional to the lattice constant which can be calculated via the results of XRD; thus, $D_{3.5 \mathrm{Ru}} / D_{2.5 \mathrm{Ru}}=\left(K_{3.5 \mathrm{Ru}} V_{\mathrm{m} 2.5 \mathrm{Ru}}\right) /$ $\left(K_{2.5 \mathrm{Ru}} V_{\mathrm{m} 3.5 \mathrm{Ru}}\right)$. Based on Fig. 8, $K_{2.5 \mathrm{Ru}}>K_{3.5 \mathrm{Ru}}$; therefore, $K_{3.5 \mathrm{Ru}} / K_{2.5 \mathrm{Ru}}<1$. On the other hand, the lattice constant of the $\gamma^{\prime}$ of the two alloys is $0.35886 \mathrm{~nm}$ and $0.35922 \mathrm{~nm}$, respectively, which means that $V_{\mathrm{m} 2.5 \mathrm{Ru}} / V_{\mathrm{m} 3.5 \mathrm{Ru}}<1$. Hence, $D_{3.5 \mathrm{Ru}} / D_{2.5 \mathrm{Ru}}<1$ has been acquired, which shows that the increase in $\mathrm{Ru}$ decreases the diffusion coefficient. Besides, based on the change of the size of $\gamma^{\prime}$ phase, the average size of the rafted $\gamma^{\prime}$ phase increases slowly during the long-term aging, which means that the consumption of elements is low. If the diffusion coefficient was high, the average size would be coarsening rapidly, which also demonstrates that the diffusion coefficient reduces with the increase in $\mathrm{Ru}$. Moreover, the low diffusion coefficient can provide competent consumption of elements.
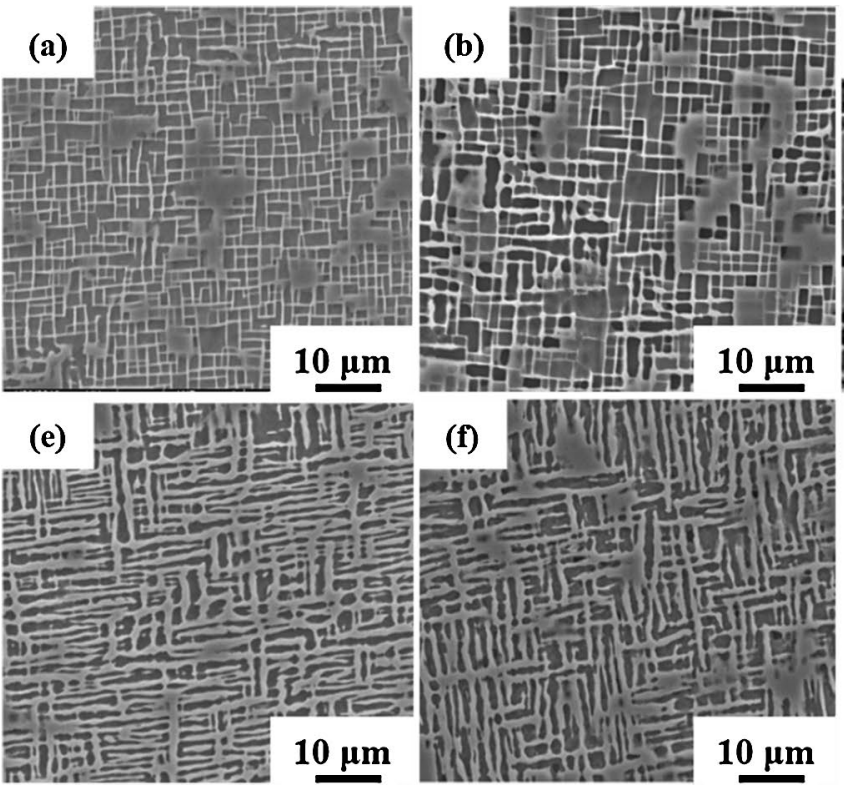

The controlling mechanism of the $\gamma^{\prime}$ precipitates coarsening of alloy 3.5 Ru has been obtained, while the controlling mechanism of the alloy $2.5 \mathrm{Ru}$ should be further investigated. According to the LSW theory, when the $\gamma^{\prime}$ precipitates coarsening is controlled by the interface reaction, the relationship between the $\gamma^{\prime}$ size and long-term aging time can be shown as the following formula [24]:

$\bar{r}^{2}-\bar{r}_{0}^{2}=K t$.

Therefore, fitting straight line of $(a / 2)^{2}-\left(a_{0} / 2\right)^{2}$ versus $t$ is established (as shown in Fig. 7b). The interface reaction determines the $\gamma^{\prime}$ precipitates coarsening of alloy $2.5 \mathrm{Ru}$ based on the excellent linear fit.

Based on the above results, the influence of $\mathrm{Ru}$ on the microstructural evolution can be summarized as follows: (a) The $\gamma / \gamma^{\prime}$ lattice misfit of the full heat-treated microstructures of the two alloys is $-0.072 \%$ and $-0.178 \%$ according to the XRD results. Hence, the elastic strain energy is increasingly larger on the $\gamma / \gamma^{\prime}$ interface, which promotes the formation of more uniform and cuboidal $\gamma^{\prime}$ phase [25-28]. (b) The higher elastic strain energy of the alloy 3.5 Ru provides plenty of power for the formation of the rafted $\gamma^{\prime}$ phase [29]. Therefore, the rafted $\gamma^{\prime}$ phase emerges at the origination of long-term aging under the combined action of elevated temperature. However, due to the low elastic strain energy, $\gamma^{\prime}$ phase of the alloy $2.5 \mathrm{Ru}$ still keeps cubical until 500 h. (c) Based on the previous linear fit, interface reaction and diffusion are the controlling mechanism of the $\gamma^{\prime}$ coarsening of the alloy $2.5 \mathrm{Ru}$

Fig. 8 Microstructures of the two alloys after long-term aging at $1100{ }^{\circ} \mathrm{C}$ : a $100 \mathrm{~h}, \mathbf{b} 200 \mathrm{~h}, \mathbf{c} 500 \mathrm{~h}, \mathbf{d} 1000 \mathrm{~h}$ of alloy $2.5 \mathrm{Ru}$; e $100 \mathrm{~h}, \mathbf{f} 200 \mathrm{~h}$, g $500 \mathrm{~h}, \mathbf{h} 1000 \mathrm{~h}$ of alloy $3.5 \mathrm{Ru}$ 
and 3.5 Ru during the long-term aging, respectively. In fact, both of the two controlling mechanisms exist simultaneously throughout the long-term aging experiments [24, 30]. What matters is which one plays the leading role. The addition of Ru has few effects on the diffusion coefficient of alloy $2.5 \mathrm{Ru}$ at high temperature for long-term aging. The interfacial energy gradually plays a dominant part due to the increasingly low elastic strain energy during the long-term aging experiments. To further release the interfacial energy, the $\gamma^{\prime}$ phase coarsens rapidly to increase the interfacial area [31-34] (as shown in Figs. 6a, 8). On the other hand, even if the elastic strain energy of the alloy 3.5 $\mathrm{Ru}$ has been consumed in quantities to form the rafted $\gamma^{\prime}$ phase, the increase in Ru also makes the $\gamma / \gamma^{\prime}$ lattice misfit more negative than that of alloy $2.5 \mathrm{Ru}$. Besides, the rafted $\gamma^{\prime}$ phase has a larger specific surface area [35], which can release the interfacial energy effectively. Therefore, diffusion plays the leading role in the coarsening of $\gamma^{\prime}$ phase of alloy 3.5 Ru. According to the previous Eq. (3), the diffusion coefficient of alloy $3.5 \mathrm{Ru}$ decreases with the increase in $\mathrm{Ru}$. The $\gamma^{\prime}$ phase coarsening is restrained prominently, especially in the long-term aging time of 200 to $500 \mathrm{~h}$ (as shown in Figs. 6b, 8). (d) The increase in Ru decreases the size and hinders the coarsening of $\gamma^{\prime}$ phase during the long-term aging. Moreover, the topological inversion phenomenon emerges in the alloy $2.5 \mathrm{Ru}$ after long-term aging, while the alloy $3.5 \mathrm{Ru}$ keeps stable rafted structure all through. In general, the increase in Ru improves microstructural stability during the long-term aging.

\subsection{Effect of Ru on the Evolution of TCP Phase}

Few TCP phase is observed in alloy $2.5 \mathrm{Ru}$, which is mainly induced by the combined action of $\mathrm{Ru}$, temperature, and time. The other elements, especially the Re element, exhibit "reverse partitioning" behavior during the long-term aging with the increase in Ru (as shown in Fig. 3 and Table 2), which makes the refractory elements further segregate in the $\gamma$ matrix. Besides, the segregation of the refractory elements is increasingly obvious with the increase in time at high temperature [36], which induces the supersaturation of the $\gamma$ matrix . On the other hand, the high temperature also provides dynamic for the precipitation of the TCP phase [37-39]. Therefore, the TCP phase emerges increasingly during the long-term aging of 500 to $1000 \mathrm{~h}$. Due to the rare amount of TCP phase, a large number of samples are applied to observe it. Hence, we do not deliberately use the SEM images of alloy $2.5 \mathrm{Ru}$ containing TCP phase. The TCP phase is $\mu$ phase and concentrates large quantities of $\mathrm{Co}, \mathrm{Re}, \mathrm{Mo}$, and $\mathrm{W}$ based on the results of selected area diffraction patterns (insets in Fig. 9) and EPMA (as listed in Table 3). According to the SEM and TEM images, the shape of the TCP phase is rod-like and bulk-like (as shown in Fig. 9). Figure 10 is the sketch map of the density and
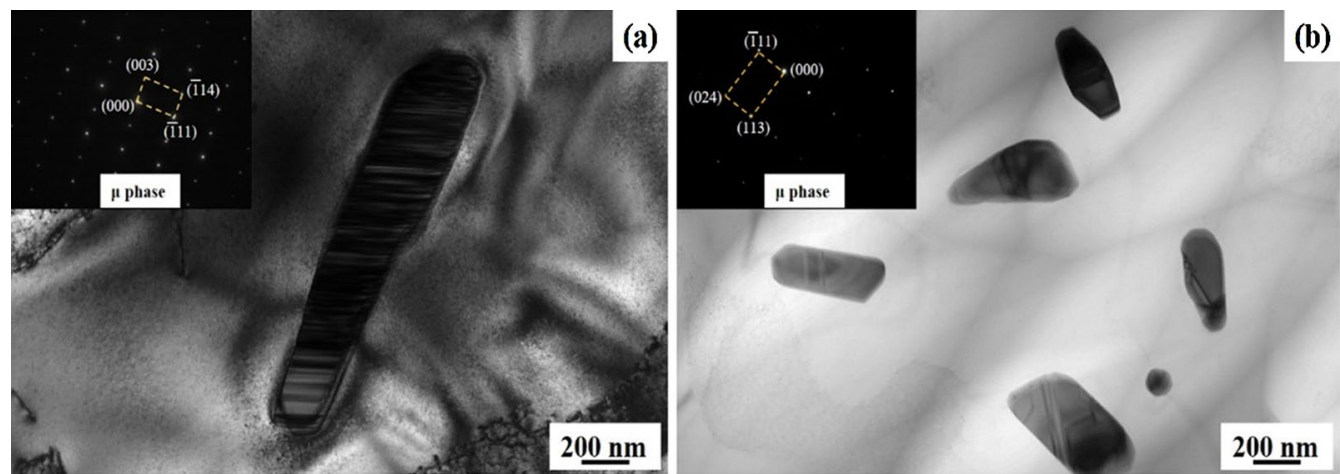

Fig. 9 TEM images and corresponding selected area diffraction patterns (insets) of the $\mu$ phase of alloy $2.5 \mathrm{Ru}$ after long-term aging of $1000 \mathrm{~h}$ at $1100{ }^{\circ} \mathrm{C}$ : a rod-like, b bulk-like

Table 2 Chemical compositions obtained by EPMA (at.\%) and the accordingly associated partitioning ratios of the two phases after 1000-h aging at $1100{ }^{\circ} \mathrm{C}$

\begin{tabular}{llllllll}
\hline Alloy & & $\mathrm{Re}$ & $\mathrm{Ru}$ & $\mathrm{Co}$ & $\mathrm{Cr}$ & $\mathrm{W}$ & Mo \\
\hline $2.5 \mathrm{Ru}$ & $\gamma$ & $3.4 \pm 0.3$ & $2.7 \pm 0.1$ & $18.1 \pm 0.3$ & $6.2 \pm 0.3$ & $2.1 \pm 0.1$ & $0.9 \pm 0.4$ \\
& $\gamma^{\prime}$ & $0.9 \pm 0.1$ & $1.3 \pm 0.2$ & $11.9 \pm 0.2$ & $2.7 \pm 0.2$ & $2.0 \pm 0.2$ & $0.4 \pm 0.2$ \\
& $K_{\mathrm{i}}$ & 3.7 & 2.1 & 1.5 & 2.3 & 1.0 & 2.1 \\
$3.5 \mathrm{Ru}$ & $\gamma$ & $3.2 \pm 0.2$ & $3.1 \pm 0.3$ & $21.9 \pm 0.5$ & $9.6 \pm 0.4$ & $3.2 \pm 0.1$ & $1.8 \pm 0.3$ \\
& $\gamma^{\prime}$ & $1.1 \pm 0.2$ & $1.7 \pm 0.1$ & $14.6 \pm 0.3$ & $4.7 \pm 0.3$ & $2.2 \pm 0.1$ & $0.8 \pm 0.5$ \\
& $K_{\mathrm{i}}$ & 2.9 & 1.8 & 1.5 & 2.1 & 1.2 & 2.1 \\
\hline
\end{tabular}


Table 3 Compositions of TCP phase in the alloy $2.5 \mathrm{Ru}$ (wt.\%)

\begin{tabular}{llllllll}
\hline $\mathrm{Cr}$ & $\mathrm{Co}$ & $\mathrm{W}$ & $\mathrm{Mo}$ & $\mathrm{Ru}$ & $\mathrm{Re}$ & $\mathrm{Ta}$ & $\mathrm{Ni}$ \\
\hline 6.3 & 11.4 & 19.1 & 6.3 & 2.7 & 33.4 & 5.4 & $\mathrm{Bal}$ \\
\hline
\end{tabular}

Fig. 10 Sketch map of possible microstructural evolution of the $\mu$ phase from 500 to $1000 \mathrm{~h}$ in alloy $2.5 \mathrm{Ru}$

shape of the TCP phase during the long-term aging of 500 to $1000 \mathrm{~h}$, which exhibits the evolution of the TCP phase. A few bulk-like TCP phases emerge firstly due to the low formation dynamic and small consumption of refractory elements. Two shapes of the TCP phase are both observed with a further increase in time. As time goes by, the high density of the TCP phase is observed at $1000 \mathrm{~h}$.

On the whole, the TCP phase emerges seldom in the research stage of the alloy containing $\mathrm{Ru}$. Moreover, the creep lives of the two experimental alloys at $1140{ }^{\circ} \mathrm{C}$ $/ 137 \mathrm{MPa}$ are $88.92 \mathrm{~h}$ and $144.9 \mathrm{~h}$, respectively, which means that the few TCP phases are harmful to the mechanical properties. The overall performance of the alloys is significantly improved with the increase in $\mathrm{Ru}$, which is discussed in other papers. This study aims to contribute to this growing area of research by exploring the influence of $\mathrm{Ru}$ on the microstructural evolution of the new generation superalloy during the long-term aging.

\section{Conclusions}

(1) The $\gamma / \gamma^{\prime}$ lattice misfit of the full heat-treated microstructures is more negative with the increase in $\mathrm{Ru}$, which makes the $\gamma^{\prime}$ particles more even and cuboidal.

(2) According to the LSW theory, the $\gamma^{\prime}$ coarsening of the alloy $2.5 \mathrm{Ru}$ and $3.5 \mathrm{Ru}$ is controlled by interface reaction and diffusion during the long-term aging, respectively. Besides, the increase in Ru decreases the diffusion coefficient and then restrains the process of the $\gamma^{\prime}$ coarsening
(3) The increment of $\mathrm{Ru}$ content induces "reverse partitioning" behavior on other elements, especially the Re element, during the long-term aging. Hence, the occurrence of few TCP phase of alloy $2.5 \mathrm{Ru}$ is attributed to the combined action of time, high temperature, and the supersaturation of the $\gamma$ matrix. Moreover, the TCP phase is determined as the $\mu$ phase, which has high levels of Co, Re, Mo, and W.

Acknowledgements This work was financially supported by the National Science and Technology Major Project (No. 2017VI-0002-0072), the National Key R\&D Program of China (No. 2017YFA0700704), the National Natural Science Foundation of China (Nos. 51671188, 51601192 and 51701210), the Youth Innovation Promotion Association, Chinese Academy of Sciences and State Key Lab of Advanced Metals and Materials Open Fund (No. 2018-Z07).

\section{References}

[1] L. Liu, J. Meng, J.L. Liu, H.F. Zhang, X.D. Sun, Y.Z. Zhou, Acta Metall. Sin.-Engl. Lett. 32, 381 (2019)

[2] R.C. Reed, The superalloys: fundaments and applications (Cambridge University Press, Cambridge, 2006)

[3] Y.B. Hu, T.S. Cao, C.Q. Cheng, L. Zhang, J. Zhao, Appl. Surf. Sci. 209, 484 (2019)

[4] P.J. Warren, A. Cerezo, G.D.W. Smith, Mater. Sci. Eng. A 250, 88 (1998)

[5] A. Epishin, U. Brückner, P.D. Portella, T. Link, Scr. Mater. 48, 455 (2003)

[6] J. Zhang, L.H. Lou, Acta Metall. Sin. 54, 1637 (2018). (in Chinese)

[7] A.C. Yeh, A. Sato, T. Kobayashi, H. Harada, Mater. Sci. Eng. A 490, 445 (2008) 
[8] F. Sun, J.X. Zhang, P. Liu, Q. Feng, X.D. Han, S.C. Mao, J. Alloys Compd. 536, 80 (2012)

[9] B. Seiser, R. Drautz, D.G. Pettifor, Acta Mater. 59, 749 (2011)

[10] R. Rettig, A. Heckl, R.F. Singer, Adv. Mater. Res. 278, 180 (2011)

[11] X.P. Tan, J.L. Liu, X.P. Song, T. Jin, X.F. Sun, Z.Q. Hu, J. Mater. Sci. Technol. 27, 889 (2011)

[12] W. Sun, X.Z. Qin, J.T. Guo, L.H. Lou, Acta Metall. Sin. 51, 67 (2015). (in Chinese)

[13] Y. Chao, W. Huan, T.G. Jian, Y.Q. He, Mater. Sci. Forum. 816, $546(2015)$

[14] J.V. Goerler, I. Lopez-Galilea, L. Mujic-Roncery, O. Shchyglo, W. Theisen, I. Steinbacha, Acta Mater. 124, 151 (2017)

[15] M.V. Acharya, G.E. Fuchs, Mater. Sci. Eng. A 381, 143 (2004)

[16] J.Y. Chen, Q. Feng, Z.Q. Sun, Scr. Mater. 63, 795 (2010)

[17] X.P. Tan, J.L. Liu, T. Jin, Z.Q. Hu, H.U. Hong, B.G. Choi, I.S. Kim, C.Y. Jo, Mater. Sci. Eng. A 528, 8381 (2011)

[18] J.J. Huo, Q.Y. Shi, Y.R. Zheng, Q. Feng, J. Alloys Compd. 15, 460 (2017)

[19] J.X. Zhang, T. Murakumo, Y. Koizumi, H. Harada, J. Mater. Sci. 38, 4883 (2003)

[20] W. Song, X.G. Wang, J.G. Li, L.H. Ye, G.C. Hou, Y.H. Yang, J.L. Liu, J.D. Liu, W.L. Pei, Y.Z. Zhou, X.F. Sun, Mater. Sci. Eng. A 772, 138646 (2020)

[21] A. Epishin, T. Link, U. Brückner, P.D. Portella, Acta Mater. 49, $4017(2001)$

[22] A.F. Giamei, D.L. Anton, Metall. Trans. 16, 1997 (1985)

[23] E.H.V.D. Molen, J.M. Oblak, O.H. Kriege, Metall. Trans. 2, 1627 (1971)

[24] W.A. Sun, Acta Mater. 55, 313 (2007)
[25] J. Komenda, P.J. Henderson, Scr. Mater. 37, 1821 (1997)

[26] T. Link, S. Zabler, A. Epishin, A. Haibel, M. Bansal, X. Thibault, Mater. Sci. Eng. A 425, 47 (2006)

[27] V.A. Vorontsov, J.S. Barnard, K.M. Rahman, H.Y. Yan, P.A. Midgley, D. Dye, Acta Mater. 120, 14 (2016)

[28] J.W. Christian, Mater. Today 6, 53 (2003)

[29] Z.H. Tan, X.G. Wang, L.H. Ye, G.C. Hou, R. Li, Y.H. Yang, J.L. Liu, J.D. Liu, L. Yang, B. Wang, P. Dong, J.G. Li, Y.Z. Zhou, X.F. Sun, Mater. Sci. Eng. A 761, 138042 (2019)

[30] S. Lay, J.M. Missiaen, R. Bonnet, Scr. Mater. 35, 885 (1996)

[31] W. Sun, X.Z. Qin, J.T. Guo, L.H. Lou, L.Z. Zhou, Acta Metall. Sin. 51, 67 (2015). (in Chinese)

[32] Q.Z. Gao, Y.J. Jiang, Z.Y. Liu, Mater. Sci. Eng. A 779, 139139 (2020)

[33] J.Y. Chen, B. Zhao, Q. Feng, L.M. Cao, Z.Q. Sun, Acta Metall. Sin. 46, 897 (2010). (in Chinese)

[34] Z.Y. Liu, Q.Z. Gao, H.L. Zhang, Mater. Sci. Eng. A 755, 106 (2019)

[35] A. Heckl, S. Neumeier, M. Göken, R.F. Singer, Mater. Sci. Eng. A 528, 3435 (2011)

[36] B. Wang, J. Zhang, X.J. Pan, T.W. Huang, L. Liu, H.Z. Fu, Acta Metall. Sin. 53, 298 (2017). (in Chinese)

[37] W.Z. Wang, T. Jin, J.L. Liu, X.F. Sun, H.R. Guan, Z.Q. Hu, Mater. Sci. Eng. A 148, 479 (2008)

[38] W.Y. Ma, Y.F. Han, S.S. Li, Y.R. Zheng, S.C. Gong, Acta Metall. Sin. 42, 1191 (2006). (in Chinese)

[39] H.B. Long, Y.N. Liu, S.C. Mao, H. Wei, J.X. Zhang, Q.S. Deng, Y.H. Chen, Z. Zhang, X.D. Han, Scr. Mater. 157, 100 (2018) 